\title{
Rural Healthcare Systems: An Analysis of the Challenges of accessing healthcare facilities among the rural households of Kerala
}

\author{
Krishnan Kutty. V. \\ Assistant Professor of Economics, Government College, Kodanchery - Kozhikode - Kerala. \\ Mail: kkmapprom@gmail.com \\ DOI: 10.29322/IJSRP.11.10.2021.p11837 \\ http://dx.doi.org/10.29322/IJSRP.11.10.2021.p11837
}

\begin{abstract}
According to US congress (1988), "The access to healthcare is defined as the potential and actual entry of a group of population in to the health and healthcare delivery system". That the ability to utilize the healthcare facilities and the availability of qualitive care were basically determine the accessibility of healthcare facilities. Regression and the Structural Equation Model (SEM) used to test the hypothesis and analyze the objective. The workforce shortage (0.434), poor health literacy (0.513), poor service offered $(0.593)$, poor health workers attitude (0.489), cost of health services (0.404), insufficient skills of health workers $(0.696)$ is the most of the challenging factor for accessing healthcare services/facilities.
\end{abstract}

Keywords: Accessibility, Healthcare, variable, Regression and Factor analysis

\section{Introduction}

Access to health, would depend on availability, awareness, affordability and the accessibility to healthcare services" (Uplekar and George - 1994). The access to healthcare affects one's own overall physical, social, mental status and the quality of life. Inaccessibility of healthcare services create the inequality in the society; especially among the rural people. The inequalities in the access to health services are the barrier to equity, inequality in availability, affordable and utilization of health care. The barriers to accessing healthcare services are unmet health needs, delay of receiving the appropriate care, inability to get preventive services. financial burden and the preventable hospitalization. Therefore, the challenges of accessing healthcare facilities for healthcare services among the rural households across the Kerala are categories in to eight items like the workforce shortage $(\mathrm{C} 1)$, poor health literacy $(\mathrm{C} 2)$, and poor services offered(C3), poor health workers attitude(C4), cost of services(C5), insufficient skills of health workers(C6), cultural practices(C7) and the distance to the healthcare center(C8).

\section{Objective of the study}

To analyse the Challenges of accessing healthcare service/facilities among the rural households.

\section{General hypothesis}

There is no significant difference between the Challenges of accessing categories in the healthcare service/facilities.

\section{Methodology of the study}


Both primary and secondary data were used and primary data were collected from the 675 rural households by using structured interview schedule.

\section{Tools used for analysis}

Regression and the Structural Equation Model (SEM) used to test the hypothesis and evaluate the objective. For the analysis initially an input model was developed by using AMOS-18 graphics. The rectangle represents observed factors, ovals in drawn in the diagram represents unobserved variable. The curved double headed arrows represent correlations or co-variances among the unobserved variables and the straight headed arrow represents the factor loadings of the observed variables. The small circles with arrows pointing from the circles to the observed variables represent errors /unique factors, which are also known as squared multiple correlation of the standard error. This initial model is refined to reach the final model. Firstly, consider measurement model of factors to test the convergent validity and then considered the various factors under awareness regarding the consumer rights.

\section{Major results of the analysis}

In order to analyse the challenges of accessing healthcare facilities among the rural households, the alternative hypothesis is made on the challenges of accessing categories were:

$\mathbf{H}_{1}$ : $\mathrm{C} 1$ is a challenge of accessing healthcare facilities

$\mathbf{H}_{2}$ : $\mathrm{C} 2$ is a challenge of accessing healthcare facilities

H3: C3 is a challenge of accessing healthcare facilities

$\mathbf{H}_{4}$ : $\mathrm{C} 4$ is a challenge of accessing healthcare facilities

H5: C5 is a challenge of accessing healthcare facilities

$\mathbf{H}_{6}$ : C6 is a challenge of accessing healthcare facilities

$\mathbf{H}_{7}$ : C7 is a challenge of accessing healthcare facilities

Hs: C8 is a challenge of accessing healthcare facilities

Table 1

Model fit Indices for CFA - Challenges of accessing healthcare facilities

\begin{tabular}{|c|c|c|c|c|c|c|c|c|c|c|c|c|}
\hline & $\chi^{2}$ & DF & $\mathbf{P}$ & $\begin{array}{c}\text { Normed } \\
\chi^{2}\end{array}$ & GFI & AGFI & NFI & TLI & CFI & RMR & RMSEA & $\begin{array}{l}\text { Source: } \\
\text { Primary Data }\end{array}$ \\
\hline $\begin{array}{c}\text { Challenges of } \\
\text { accessing } \\
\text { healthcare } \\
\text { facilities }\end{array}$ & 9.364 & 11 & .588 & .851 & .997 & .989 & .988 & 1.006 & 1.00 & .008 & 0.00 & All the \\
\hline $\begin{array}{c}\text { Recommended } \\
\text { value }\end{array}$ & & & & $<5$ & $>0.9$ & $>0.9$ & $>0.9$ & $>0.9$ & $>0.9$ & $<1$ & $<1$ & \\
\hline
\end{tabular}

attributes/categories loaded significantly on the latent constructs. The value of the fit indices indicates a reasonable fit of the measurement model with data. The multiple regression model for the challenges of accessing healthcare facilities and in table 2 , present the regression coefficients for the challenges of accessing healthcare services.

$$
Y=\beta_{1}+\beta_{2} X_{2}+\beta_{3} X_{3}+\beta_{4} X_{4}+\beta_{5} X_{5}+\beta_{6} X_{6}+\beta_{7} X_{7}+\beta_{8} X_{8}+\beta_{9} X_{9}
$$




$$
\begin{aligned}
& \mathrm{Y}=\text { Challenges of accessing healthcare facilities } \\
& \beta_{1} \ldots \ldots \ldots . . . \beta_{9}=\text { Regression coefficients } \\
& \mathrm{X}_{2}=\text { Workforce shortage } \\
& \mathrm{X}_{3}=\text { Poor health literacy } \\
& \mathrm{X}_{4}=\text { Poor service offered } \\
& \mathrm{X}_{5}=\text { Poor health workers' attitude } \\
& \mathrm{X}_{6}=\text { Cost of services } \\
& \mathrm{X}_{7}=\text { Insufficient skills of health workers } \\
& \mathrm{X}_{8}=\text { Cultural practices } \\
& \mathrm{X}_{9}=\text { Distance to the healthcare center }
\end{aligned}
$$

Table 2

The regression Coefficients - Challenges of accessing healthcare facilities

\begin{tabular}{|c|c|c|c|c|c|}
\hline $\begin{array}{c}\text { Factors/ Latent } \\
\text { Variables } \\
\text { (Dependent } \\
\text { Variable) }\end{array}$ & $\begin{array}{c}\text { Construct } \\
\text { (Independent } \\
\text { Variable) }\end{array}$ & $\begin{array}{c}\text { Regression } \\
\text { Coefficient }\end{array}$ & $\mathbf{C . R .}$ & $\mathbf{P}$ & $\begin{array}{c}\text { Variance } \\
\text { explained } \\
(\boldsymbol{\%})\end{array}$ \\
\hline \multirow{4}{*}{$\begin{array}{c}\text { Challenges of } \\
\text { accessing healthcare } \\
\text { facilities }\end{array}$} & $\mathrm{C} 1$ & 0.434 & 12.049 & $<0.001$ & 18.8 \\
\cline { 2 - 6 } & $\mathrm{C} 2$ & 0.513 & 14.693 & $<0.001$ & 26.3 \\
\cline { 2 - 6 } & $\mathrm{C} 3$ & 0.593 & 17.687 & $<0.001$ & 23.9 \\
\cline { 2 - 6 } & $\mathrm{C} 4$ & 0.489 & 13.862 & $<0.001$ & 9.2 \\
\cline { 2 - 6 } & $\mathrm{C} 5$ & 0.404 & 15.138 & $<0.001$ & 15.5 \\
\cline { 2 - 6 } & $\mathrm{C} 6$ & 0.696 & 22.281 & $<0.001$ & 3.0 \\
\hline
\end{tabular}

Source: Primary Data

$\mathbf{H}_{1}$ : $\mathbf{C} 1$ is a challenge of accessing healthcare facilities

The results exhibited in Table 2 revealed that the regulatory construct $\mathrm{C} 1$ is a challenge of accessing healthcare facilities as the standardised direct effect of this construct on Challenges is 0.434 , which is more than the recommended value of 0.4 ( $p$ value significant). So that the hypothesis $\mathrm{H}_{1}$ is accepted and concludes that $\mathrm{C} 1$ (Work force shortage) is a challenge of accessing healthcare facilities.

$\mathbf{H}_{2}$ : $\mathrm{C} 2$ is a challenge of accessing healthcare facilities

The results exhibited in Table 2 revealed that the regulatory construct $\mathrm{C} 2$ is a challenge of accessing healthcare facilities as the standardised direct effect of this construct on Challenges is 0.513 , which is more than the recommended value of 0.4 ( $p$ value This publication is licensed under Creative Commons Attribution CC BY. 
ISSN 2250-3153

significant). Therefore, the hypothesis $\mathrm{H}_{2}$ is accepted and concludes that $\mathrm{C} 2$ (Poor health literacy) is a challenge of accessing healthcare facilities.

H3: $\mathrm{C} 3$ is a challenge of accessing healthcare facilities

The results exhibited in Table 2 revealed that the regulatory construct $\mathrm{C} 3$ is a challenge of accessing healthcare facilities as the standardised direct effect of this construct on Challenges is 0.593 , which is more than the recommended value of 0.4 ( $\mathrm{p}$ value significant). Hence, the hypothesis $\mathrm{H}_{3}$ is accepted and concludes that $\mathrm{C} 3$ (Poor services offered) is a challenge of accessing healthcare facilities.

H4: $\mathrm{C} 4$ is a challenge of accessing healthcare facilities

The results exhibited in Table 2 revealed that the regulatory construct $\mathrm{C} 4$ is a challenge of accessing healthcare facilities as the standardised direct effect of this construct on Challenges is 0.489 , which is more than the recommended value of 0.4 ( $p$ value significant). So that, the hypothesis $\mathrm{H}_{4}$ is accepted and concludes that $\mathrm{C} 4$ (Poor health workers attitude) is a challenge of accessing healthcare facilities.

H5: C5 is a challenge of accessing healthcare facilities

The results exhibited in Table 2 revealed that the regulatory construct C5 is not a challenge of accessing healthcare facilities as the standardised direct effect of this construct on Challenges is 0.404, which is more than the recommended value of 0.4.(p value significant) So the hypothesis $\mathrm{H}_{5}$ is accepted and concludes that $\mathrm{C} 5$ (Cost of health services) is a challenge of accessing healthcare facilities.

$\mathbf{H}_{6}$ : $\mathrm{C} 6$ is a challenge of accessing healthcare facilities

The results exhibited in Table 2 revealed that the regulatory construct C6 is a challenge of accessing healthcare facilities as the standardised direct effect of this construct on Challenges is 0.696 , which is more than the recommended value of 0.4 ( $p$ value significant). Therefore, the hypothesis $\mathrm{H}_{6}$ is accepted and concludes that $\mathrm{C} 6$ (Insufficient skills of health workers) is a challenge of accessing healthcare facilities.

H7: $\mathrm{C} 7$ is a challenge of accessing healthcare facilities

The results exhibited in Table 2 revealed that the regulatory construct C7 is not a challenge of accessing healthcare facilities as the standardised direct effect of this construct on Challenges is 0.172 , which is less than the recommended value of 0.4. So the hypothesis $\mathrm{H}_{7}$ is rejected and concludes that $\mathrm{C} 7$ (Cultural belief/Practices) is not a challenge of accessing healthcare facilities.

$\mathbf{H}_{8}$ : C8 is a challenge of accessing healthcare facilities

The results exhibited in Table 2 revealed that the regulatory construct $\mathrm{C} 8$ is not a challenge of accessing healthcare facilities as the standardised direct effect of this construct on Challenges is 0.139 , which is less than the recommended value of 0.4. So, the hypothesis $\mathrm{H}_{8}$ is rejected and concludes that C8 (Distance to the healthcare center) is not a challenge of accessing healthcare facilities.

Therefore, the fitted multiple regression coefficient shows that the cultural practices and the distance to the healthcare centre is not a challenging factor for accessing the healthcare facilities.

$$
\begin{gathered}
Y=\beta_{1}+\beta_{2} X_{2}+\beta_{3} X_{3}+\beta_{4} X_{4}+\beta_{5} X_{5}+\beta_{6} X_{6}+\beta_{7} X_{7}+\beta_{8} X_{8}+\beta_{9} X_{9} \\
Y=\beta_{1}+0.434 X_{2}+0.513 X_{3}+0.593 X_{4}+0.489 X_{5}+0.404 X_{6}+0.696 X_{7}+\beta_{8} X_{8}
\end{gathered}
$$

\section{Conclusion}

Based on the regression coefficient, conclude that; workforce shortage (0.434), poor health literacy (0.513), poor service offered (0.593), poor health workers attitude (0.489), cost of health services (0.404), insufficient skills of health workers $(0.696)$ is the most of the challenging factor for accessing healthcare services/facilities and Cultural belief/practices (0.172) and distance to the healthcare center (0.139) is not a challenging factor for accessing healthcare facilities.

This publication is licensed under Creative Commons Attribution CC BY.

http://dx.doi.org/10.29322/IJSRP.11.10.2021.p11837

www.ijsrp.org 


\section{Reference}

R. Penchansky and J.W.Thomas (1981) “ The concept of access”, Med care, 19 (2) - pp 127 - 140.

A. Oliver and E. Mossialos (2004) "Equity of access to health care: Outlining the foundation for action", Journal of Epidemiol community health -55 , pp $655-658$.

Simon, T D (2007) Healthcare Accessibility and Socio - Economic Groups: A study of Kerala, Phd thesis, university of Calicut.

Strasser, Roger (2003)," Rural health around the world: Challenges and Solutions" Family Practice, Oxford University Press, 20 (4), $457-463$.

Pillai RK, Williams SV, Glick HA et al. 2003. Factors affecting decisions to seek treatment for sick children in Kerala, India. Social Science and Medicine 57: 783-90.

Munoz UH, Kallestal C. Geographical accessibility and spatial coverage modeling of the primary health care network in the Western Province of Rwanda. Int J Health Geogr, 2012; 11:40-50.

Kronfol NM. Access and barriers to health care delivery in Arab countries: a review. East Mediterr Health J, 2012 ; 18 : $1239-1246$. 